\title{
Sepsis nach Fußball
}

\section{Lebensgefahr durch ein paar Schürfwunden}

\begin{abstract}
Abschürfungen und blaue Flecken ziehen sich Kinder beim Sport schnell mal zu - ebenso schnell werden diese dann wieder vergessen. Einem 14-jährigen Patienten jedoch kostete so ein "Bagatelltrauma" beim Fußballspielen beinahe das Leben!
\end{abstract}

\begin{abstract}
Übersät mit Schürfwunden und zunehmender Verschlechterung des Allgemeinzustands, Fieber, Diarrhö, blutig tingiertem Erbrechen und Hämaturie wurde der Junge in die Kinderklinik eingewiesen, schreiben Dr. Birte Tröger und Kollegen in der „Monatsschrift Kinderheilkunde“.
\end{abstract}

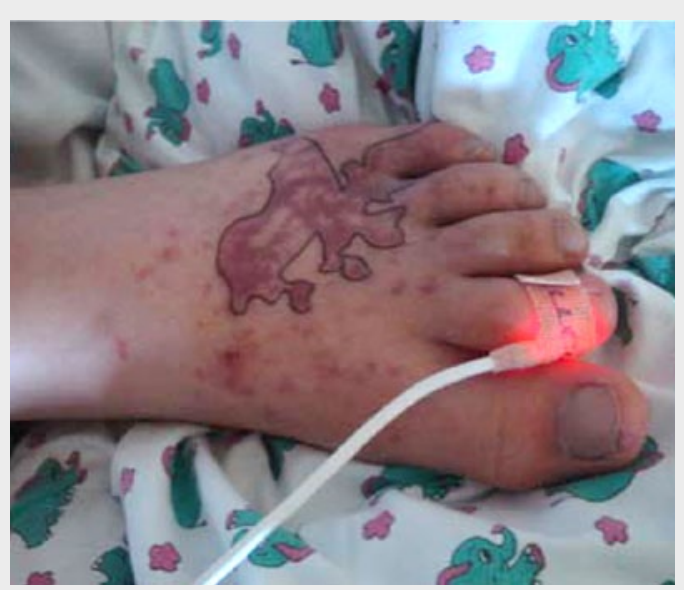

1 Ekchymosen am linken Fußrücken.

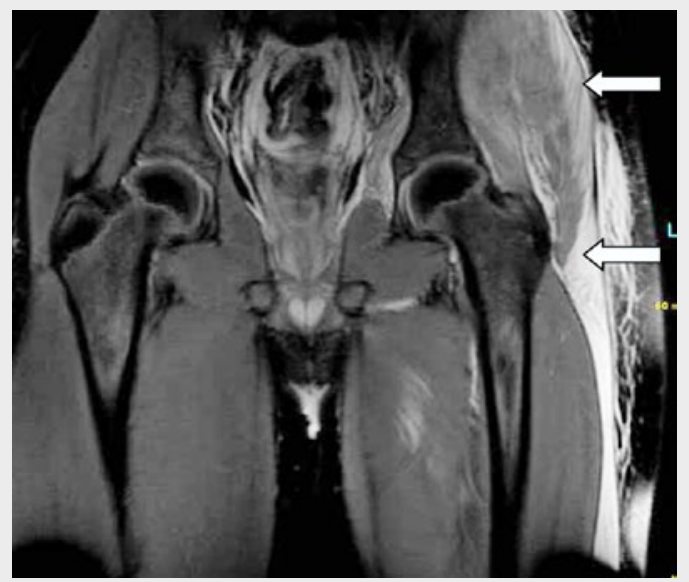

2 Verstärkte Kontrastmittelaufnahme der lateralen Oberschenkelmuskulatur links im MRT-Bild.
In der Anamnese berichtete er lediglich von einem Sturz auf die linke Hüfte beim Fußballspielen. Als Vorerkrankung war eine juvenile idiopathische Arthritis (JIA) bekannt, weswegen der junge Patient ein NSAR einnahm.

Bei der klinischen Untersuchung fanden sich Petechien an Stirn, Wangen und an der Mundschleimhaut. Die Füße waren kalt und blass, im Verlauf bildeten sich an beiden Fußrücken Ekchymosen (Abb. 1). Der Patient hatte starke Schmerzen bei Palpation des linken Hüftgelenks. Zudem war er tachykard (Herzfrequenz 148/min); seine Atemfrequenz war erhöht (50/min). Die Laborwerte zeigten u.a. eine hohe Zahl an unreifen Neutrophilen im Blut (41\%), erhöhtes C-reaktives Protein $(285 \mathrm{mg} / \mathrm{l})$, sowie eine Thrombozytopenie (6/nl), niedrigen Quick-Wert (39\%) und eine erhöhte partielle Thromboplastinzeit (55 s). Auch D-Dimere (9451 ng/ $\mathrm{ml})$ ließen sich nachweisen.

\section{Streptokokken in der Blutkultur}

Aufgrund der starken Schmerzen im Bereich der linken Hüfte wurde ein MRT veranlasst, das den Verdacht auf eine Myositis bestätigten konnte (Abb. 2). In der Blutkultur fand sich dann der Ursprung des Übels: ß-hämolysierende Streptokokken der Serogruppe A. Der Patient hatte ein streptokokkenassoziiertes toxisches Schocksyndrom (STSS) entwickelt.

Dabei handelt es sich um eine Infektion durch Streptokokken der Gruppe A, die zu Schock und Multiorganversagen führt. Die Bakterientoxine wirken als Superantigene; sie aktivieren das Immunsystem, was die Ausschüttung inflammatorische Zytokine zur Folge hat. Meist befindet sich die Eintrittspforte im HNO-Bereich oder der Haut. Kann keine Eintrittspforte ermittelt werden, sind oft tiefe Infektionen der Grund, wie z. B. in diesem Fall, eine Myositis. Sie tritt 48 bis 72 Stunden nach einem Bagatelltrauma ohne sichtbare Hautverletzung auf. Bei einer solchen gangränösen Myositis - beträgt die Mortalität 80-100\%. Als Risikofaktoren für ein STSS gelten neben viralen Infektionen, stumpfen Traumen und chirurgischen Interventionen auch die Einnahme nichtsteoridaler Antiphlogistika.

\section{Multiorganversagen bestimmt den Verlauf}

Für den Patienten bestand Lebensgefahr, es musste schnell gehandelt werden. Die linke Oberschenkelmuskulatur wurde sofort großflächig gespalten, zum Vorschein kamen zahlreiche nekrotische Veränderungen. Nach ausgedehntem Wunddébridement fanden tägliche Verbandswechsel und Spülungen der Muskellogen mit antiseptischen Lösungen statt.

Im Verlauf entwickelte der Patient ein Multiorganversagen mit disseminierter intravasaler Gerinnung, dialysepflichtigem Nierenversagen, katecholaminpflichtiger arterieller Hypotension, ARDS („acute respiratory distress syndrome“) und Leberbeteiligung. Nach drei Tagen stabilisierte sich der Zustand des Patienten. Sieben Tage nach der Aufnahme erfolgte die Extubation, einen Tag später konnte die Hämodialyse beendet werden. Die Wundfläche des linken Oberschenkels wurde sekundär verschlossen.

Trotz früher operativer Behandlung und sofortiger i.v. Antibiose, haben das STSS und die assoziierte Myositis eine schlechte Prognose. Der Verlauf ist wesentlich durch das Ausmaß des Multiorganversagens bestimmt. Für den jungen Fußballspieler ist alles glücklicherweise gut ausgegangen.

(Katharina Grzegorek)

Tröger B et al, Sepsis mit Multiorganversagen nach Bagatelltrauma, Monatsschr Kinderheilkd 2011, 159:809-812 